
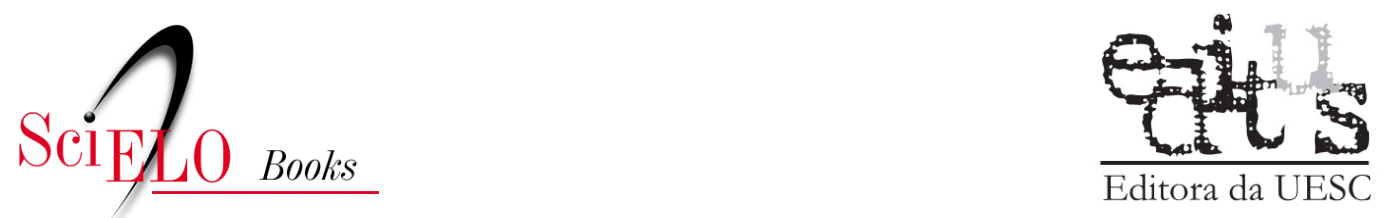

\title{
Representações sociais de idosos sobre a adaptação em uma instituição de longa permanência
}

\author{
Silvia Virginia Coutinho Areosa \\ Cristiane Redin Freitas \\ Juliana Eisenhardt
}

\section{SciELO Books / SciELO Livros / SciELO Libros}

AREOSA, S. V. C., FREITAS, C. R., and EISENHARDT, J. Representações sociais de idosos sobre a adaptação em uma instituição de longa permanência. In: D'ALENCAR, R. S., ed. A representação social na construção da velhice [online]. Ilhéus, BA: EDITUS. 2017, pp. 37-60. ISBN: 978-85-7455-486-0. https://doi.org/10.7476/9788574554860.0003.

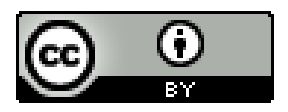

All the contents of this work, except where otherwise noted, is licensed under a Creative Commons Attribution 4.0 International license.

Todo o conteúdo deste trabalho, exceto quando houver ressalva, é publicado sob a licença Creative Commons Atribição 4.0.

Todo el contenido de esta obra, excepto donde se indique lo contrario, está bajo licencia de la licencia Creative Commons Reconocimento 4.0. 


\title{
REPRESENTAÇÕES SOCIAIS DE IDOSOS SOBRE A ADAPTAÇÃO EM UMA INSTITUIÇÃO DE LONGA PERMANÊNCIA
}

\author{
Silvia Virginia Coutinho Areosa \\ Cristiane Redin Freitas \\ Juliana Eisenhardt
}

\section{Introdução}

Devido às menores taxas de natalidade, melhores condições de vida, progressos na medicina e avanços da saúde pública, o índice de mortalidade vem diminuindo e, com isso, o número de idosos vem aumentando em todos os países (BASSIT; WITTER, 2006). O Brasil, por sua vez, acompanha a tendência mundial e apesar da legislação estabelecer que os familiares sejam responsáveis pelos cuidados dos membros dependentes, na prática, essa obrigação tem sido transferida a outros. Neste sentido, uma alternativa que vem crescendo é a institucionalização do idoso, tanto em locais públicos como privados (CAMARANO, KANSO, 2010).

Para Zimerman (2000), alguns dos motivos que levam os familiares a optarem pela institucionalização são: dificuldades econômicas, ambientes familiares não favoráveis, ou mesmo a falta de pessoas próximas, etc. Corroborando com esses fatores, Daniel (2006) aponta que o atual 
modo de vida familiar torna dificil a conciliação com as responsabilidades de cuidador, logo, a institucionalização acaba se tornando uma solução. Contudo, para a autora, essa alternativa não é tida como positiva, pois representa um corte na história de vida e um afastamento de antigas relações pessoais do idoso.

Por outro lado, a institucionalização pode representar um possivel problema para os familiares, especialmente quando relacionada a sentimentos de culpa, decorrentes do desamparo sentido pelo idoso. Apesar disso, Amaro (2013) refere que em algumas situações, a decisão de sair de casa e morar em uma instituição é opção do idoso que não quer ser um fardo aos familiares ou que teme viver sozinho por conta de suas limitações. Nesse sentido, as famílias tendem a se aproximar mais após a institucionalização, pois a tensão envolvida com o trabalho de cuidadores se transfere para a instituição (CORREIA, 2007).

Com o intuito de investigar como ocorre o processo de adaptação de idosos em uma instituição de longa permanência, a pesquisa realizada teve como base a Teoria das Representações Sociais (MOSCOVICI, 2003). A referida Teoria procura explicar como se produz e se transforma o conhecimento gerado no cotidiano, através de conversas com os pares e ideias construídas socialmente. Para Moscovici (1961, 2012), as relações sociais estabelecidas no dia a dia são fruto de representações apreendidas por cada um e são parte de um esforço para entender o mundo e para se comunicar. Assim, os significados atribuídos à velhice e à inserção do idoso em instituições de longa permanência, objeto do presente estudo, também são representações sociais passiveis de compreensão e investigação.

Para a identificação dessas representações, foram entrevistados dez idosos que residem há menos de um ano em uma instituição de longa permanência para idosos (ILPI) de Santa Cruz do Sul/RS. Durante sua realização, os idosos foram questionados a respeito do motivo que os 
levou à institucionalização, como se passaram seus primeiros dias e quais as modificações que perceberam em suas vidas.

Conforme a literatura estudada, quando os idosos são institucionalizados passam por um processo complicado de adaptação em que sua autonomia é comprometida. Isso ocorre, porque grande parte das instituições possui uma rotina, com a qual o idoso precisa se habituar. Esse processo pode desencadear uma fase dificil para o mesmo, pois ao sair de casa sua integridade é colocada em jogo, assim como sua privacidade e liberdade. A rotina imposta pelo local altera seu modo de vida e pode constituir uma modificação identitária. (AMARO, 2013).

O que também contribui para o sentimento de perda de identidade é a forma como a instituição padroniza seus residentes, reduzindo-os a um coletivo, o que pode provocar uma espécie de despersonalização. Goffman (1996) ressaltou essa questão ao afirmar que quando o indivíduo chega a uma instituição, passa por um processo de mortificação do eu, que é relativamente padronizado de acordo com o local onde está inserido. Sobre essa questão, Guedes (2008) coloca que as reconstituições da identidade desses sujeitos seriam resultado do convívio com as pessoas da instituição, entre elas os residentes e funcionários. Assim, quanto mais preservadas as individualidades dos idosos de uma instituição, mais protegida estará sua identidade.

Acredita-se que essas reflexões tenham suma importância e devem ser difundidas, de forma que as instituições nesses moldes possam repensar seus processos de adaptação de novos residentes de maneira mais acessível, conservando o máximo da individualidade do idoso. Também, percebe-se que o trabalho nas ILPI's deve ser focado primeiramente nas necessidades dos residentes, tanto nas questões relativas à adaptação como nas práticas cotidianas da instituição, para que os idosos possam usufruir das melhores condições no final de suas vidas. 
A pesquisa desenvolvida ${ }^{1}$, de caráter transversal e qualitativa, teve como campo de estudo uma instituição de longa permanência para idosos de caráter público, localizada em Santa Cruz do Sul (RS), durante o ano de 2016. Foram realizadas entrevistas individuais e semidirigidas, que foram gravadas e transcritas, com dez idosos que estivessem residindo na instituição há menos de um ano e com a cognição preservada. Foi dada preferência para sujeitos que ingressaram na instituição durante o período da pesquisa, de forma que fosse possivel observar suas representações sociais sobre seu processo de adaptação à nova vida. Na entrevista, foram abordados os motivos do ingresso na instituição e como ocorreu o processo de adaptação na mesma, incluindo as possiveis dificuldades e facilidades que a instituição possa ter ofertado. A preferência pela pesquisa qualitativa se deu pela escolha em apreender $\mathrm{o}$ fenômeno das representações sociais dos idosos de forma ampla, o que não é favorecido pela pesquisa de cunho quantitativo. Dessa forma, os dados da realidade podem ser mais bem considerados e as representações obtidas podem ser vistas como um todo e não como apenas variáveis. Para Godoy (1995), nesse método de investigação, o pesquisador se torna peça fundamental, pois está incluso no processo. Esta maneira de conduzir a investigação vem ao encontro da pesquisa de cunho representacional, pois a Teoria das Representações Sociais (MOSCOVICI, 2003) propõe-se a interpretar os significados simbólicos e as compreensões trazidas pelos participantes, no espaço da interação que, neste caso, refere-se à instituição de longa permanência.

Compreender a perspectiva dos idosos envolve tanto o contexto histórico em que as concepções de velhice emer-

1 A pesquisa cumpriu todas as normas éticas, tendo sido aprovada pelo Comitê de Ética da Universidade de Santa Cruz do Sul, sob a CAEE 57477416.0.0000.5343. 
gem quanto o entendimento das representações sociais que elaboram sobre sua situação. Não se trata somente de conhecer sujeitos isolados em sua forma de pensar a sua inserção em uma ILPI, mas de abordar o caráter relacional dessa condição. Os dados coletados foram analisados com base no método de Análise de Conteúdo de Bardin (1977). Esse modelo de análise inicia-se com o plano das falas para depois se tornar mais complexo, pois ela ultrapassa os significados manifestos nos dados coletados. Para isso, é necessário analisar os dados de forma comparativa e também as diferentes reflexões surgidas. Esse conteúdo deve ser organizado em categorias construídas em função dos objetivos da pesquisa e discutidas à luz do referencial teórico escolhido (MINAYO, 2007).

\section{Processo de inserção dos idosos em uma insti- tuição de longa permanência: representações construidas}

Para iniciar a discussão das representações sociais surgidas nas falas dos idosos institucionalizados, pensouse em trazer uma breve referência sobre a Teoria das Representações Sociais. Essa fundamentação possibilitará o embasamento para a posterior análise dos significados da institucionalização permanente para os idosos residentes.

\section{- Representações Sociais}

Parte-se do entendimento de que as representações sociais são saberes ou conhecimentos, socialmente elaborados e partilhados, com objetivos práticos e que contribuem para a construção de realidades comuns a um grupo social (JODELET, 2007). Assim, trata-se do processo de assimilação, elaboração e transformação de temas divulgados pela ciência, academia e mídia (jornais, televisão) 
que encontram espaço fecundo na apropriação pela população em geral. Dessa forma, as informações são introjetadas e modificadas e a sua elaboração nas conversas e interações cotidianas vai construindo "tijolaços de saberes" que compõem o tecido social. O interesse da Teoria das Representações Sociais volta-se aos saberes produzidos na vida cotidiana e na compreensão de como pessoas comuns, comunidades e instituições produzem conhecimento sobre si mesmas, sobre outros e sobre os fatos sociais que são importantes a elas. Esses saberes são partilhados, pois se originam por meio de processos de comunicação, das trocas e interações entre atores sociais (GUARESCHI, 2004; JOVCHELOVITCH, 2008).

As pessoas, ao observarem seu cotidiano, pensam sobre ele e conversam com outras pessoas. Nesse processo, suas compreensões são permeadas por valores, hábitos culturais, emoções, contradições e práticas de vários tipos. O aspecto que torna as representações sociais fenômenos que transpõem uma simples reprodução de fatos e objetos do mundo é a sua função simbólica. A função simbólica permite que a representação social contenha uma dimensão criativa e produtiva, além do fato de estar aberta à sua própria contradição. Esse fato pressupõe que as representações sociais não são fechadas em si e que dão chance às contradições que elas contêm em si mesmas, provando que há nelas múltiplas dimensões devido ao seu poder criativo e inovador de construir o mundo e a realidade. Portanto, compreender a função simbólica das representações é fundamental para o reconhecimento de que os saberes possuem um potencial criativo e transcendente da realidade do mundo empírico. "Representar é tornar presente o que está ausente através do uso de simbolos" (JOVCHELOVITCH, 2008, p. 93). Como formas de conhecimento prático, as representações sociais também possibilitam uma organização e orientação às pessoas e se consolidam através de um jogo de forças: de um lado, 
pelos conteúdos que circulam na sociedade e são assimilados pela população e, de outro, pelo próprio processo de interação social e das pressões para definir uma situação de forma a confirmar e manter identidades coletivas.

Uma vez que um conteúdo é aceito e difundido, ele constitui-se como parte integrante do universo simbólico e, portanto, dos saberes das pessoas e de suas inter-relações com os outros. Jovchelovitch (2008), ao analisar a função das representações sociais em uma sociedade, refere que a mesma trata de uma teoria geral que demonstra que uma sociedade não poderia ser definida pela simples presença de um coletivo que reuniu indivíduos através de uma hierarquia de poder, como, por exemplo, através de intercâmbios baseados em interesses mútuos. Certamente, existem poder e interesse, mas para serem reconhecidos como tais devem existir representações ou valores que lhes deem sentido e, sobretudo, que se esforcem para que os indivíduos convirjam e se unam por meio de crenças que garantam sua existência comum. Isso tudo guiado por opiniões, símbolos, rituais e crenças e não simplesmente pelo conhecimento ou técnica. Todos esses aspectos que integram as representações sociais produzem um impacto nos modos de se comportar, de sentir ou de transmitir e permutar saberes.

Argumenta-se que a Teoria das Representações Sociais como embasamento para a averiguação das ideias, pensamentos e significados da institucionalização para os idosos é oportuna, no sentido em que auxilia na identificação de prováveis traços ideológicos presentes em suas explanações, ou mesmo na verificação de possiveis críticas à forma como a adaptação na instituição se concretizou. Ao iniciarmos a identificação dessas representações, apresentamos um pouco do histórico da ILPI em que foi realizado o estudo. 


\section{Histórico da instituição de longa permanência}

A instituição de longa permanência ${ }^{2}$ onde foi realizada a pesquisa localiza-se no municipio de Santa Cruz do Sul (RS). Fundada em 1948, o local tinha, inicialmente, o propósito de receber meninas solteiras grávidas que eram expulsas de suas casas. Atualmente, a instituição atende idosos em situação de risco ou vulnerabilidade. O local é reconhecido pelo Estatuto do Idoso (BRASIL, 2015) como uma Instituição de Longa Permanência para Idosos e recebe pessoas com mais de 60 anos. Apenas em casos de medidas de proteção judicial é permitido o ingresso de pessoas com idade abaixo do limite estabelecido. A instituição conta com aproximadamente 80 residentes, incluindo casos com limitações físicas sérias, deficiências mentais e até alguns casos de dependência química. Os idosos possuem acompanhamento de profissionais da enfermagem, nutrição, psicologia e fisioterapia, além de receberem os medicamentos necessários. Na instituição também são oferecidos serviços de assistência médica e jurídica. Os dias para visitação são livres, porém devem acontecer somente no turno da tarde. No caso de familiares que queiram levar o residente para algum passeio, isso pode ocorrer mediante aviso prévio e autorização da instituição.

A instituição é mantida por meio de doações da comunidade, empresas e auxílio da prefeitura. Os residentes contribuem com $70 \%$ de sua renda mensal, proveniente de aposentadoria ou pensão. Uma parte da renda dos idosos é destinada para uso próprio, para despesas médicas extras, passeios, cigarros entre outros.

Ao ingressar, o novo morador chega à instituição acompanhado de seus familiares e é apresentado à estrutura fisica do local. Além disso, o idoso passa pelo atendimento da

2 As informações sobre a instituição de longa permanência foram escritas a partir das observações realizadas no local, pois não havia nenhum histórico documentado sobre o local. 
enfermagem, no qual é verificado seu estado de saúde e coletadas informações sobre, por exemplo, medicamentos que o idoso ingere diariamente. Por fim, o idoso é levado ao seu quarto onde são retirados seus pertences, que permanecem em uma espécie de depósito e que são avaliados pelos funcionários, que separam o que pode ser utilizado e o que deve ser rejeitado. As roupas e calçados selecionados passam a ser de utilização coletiva dos moradores.

A partir da análise das representações sociais surgidas nas entrevistas com os idosos residentes da referida instituição, foram construídas quatro categorias que são apresentadas e discutidas a seguir.

\section{Motivos para a institucionalização}

Nessa categoria, são discutidos os motivos que levaram os idosos a residir na instituição de longa permanência. De acordo com a pesquisa realizada por Bessa e Silva (2008), muitos idosos acabam residindo em uma instituição desse tipo por exclusão familiar e necessidade de apoio, tanto em questões médicas como no cuidado de si. Para as autoras, porém, essa atitude poderia ser evitada se fossem efetivadas mais politicas centradas nos idosos, especialmente no que se refere à saúde, de modo que as famílias, ao receberem apoio da atenção básica, poderiam optar por permanecer com seus idosos em casa, mesmo que dependentes. Contudo, as falas dos participantes revelam que a institucionalização se dá em função da saúde e da dependência:

- Era tudo muito longe, (...) eu também não podia mais fazer comida e não tinha ninguém, assim, pra pagar (...) pra fazer as coisas lá em casa pra nós. E aquele (filho) que eu queria ficar, que ia me cuidar, faleceu, vai fazer 3 anos, agora, quinta feira. (E2). 
- Porque eles (filhos) me trouxeram porque eu tava doente. Agora tô mais melhor, mas não tô firme, isso não. Eu vim pra cá porque disseram que eu tava doente, eu não tava comendo mais, (...) não tinha coragem, só queria dormir, depois passou, agora passou. (E4).

Filho e Filho (2002) trazem como motivos para a institucionalização de idosos as condições precárias de saúde e falta de apoio familiar já mencionados, e ainda os distúrbios de comportamento, incapacidade de exercer atividades laborais e dificuldades financeiras. Desse modo, a capacidade de cuidado da família pode estar prejudicada e por esse motivo, o idoso acaba se tornando um empecilho para os familiares. Isso ocorre pela exigência, por parte do idoso, de uma atenção cotidiana intensa, o que dificulta a conciliação dessa responsabilidade com o trabalho e a familia nuclear. Por essas razões, pode haver dificuldades de encontrar um membro da família que se disponibilize e responsabilize pelo cuidado com o idoso. Em ambos os casos, a solução encontrada acaba por ser a institucionalização (PERLINI, LEITE, FURINI, 2007).

Born (1999) relata que no Brasil, por conta da falta de programas comunitários de atendimento aos idosos dependentes, as famílias buscam a institucionalização como uma solução imediata para o problema, sem antes estudar possiveis alternativas. Isso pode ser confirmado pelas falas a seguir:

- Pois é, aquele de Pantano Grande (filho) era o único, só que aquele eu notava que não gostava muito... ele saia muito né. E aí eu achei... a minha filha me disse que aqui era um lugar muito bom. (E1)

- Eu vim pra cá por causa que me deu um troço nas pernas e nos braços (AVC), dai em casa não tinha lugar para parar, (...) e ai a mulher tinha arrumado pra mim vir pra cá. Ai eu entrei aqui e tô aí até hoje. (E3)

- Eu tive uns problemas de saúde. Eu passei a não enxergar mais e eu sou sozinho, não tinha onde parar direito. (E5) 
Conforme os relatos dos entrevistados, quem propôs a institucionalização foram os filhos ou algum outro familiar que percebiam a impossibilidade do idoso viver sozinho, devido a sua situação de saúde. A respeito disso, Perlini, Leite e Furini (2007) assinalam que no momento em que a família procura um lugar para o idoso, ela busca um ambiente em que o sujeito tenha seus cuidados atendidos, assim como proporcione socialização e convivência. Isso pode ser percebido, na primeira fala supracitada, na qual o entrevistado expressa que sua filha pensou que aquele seria um lugar adequado para ele, uma vez que nem ela, nem seu irmão poderiam se responsabilizar por seus cuidados. Diante dessa questão, Santos (2003) descreve acerca da profissionalização do cuidado, que passa a ser realizado por profissionais de uma equipe interdisciplinar, colocando a família no lugar de visitante. De acordo com a autora, os familiares se submetem a regras da instituição que definem o dia e horário de visitas e o quanto eles podem fazer pelo idoso institucionalizado. Carletti e Rejani (1999) reconhecem que em algumas situações a institucionalização é necessária, porém defendem que ela aconteça de forma consensual, de maneira que a quebra dos vínculos familiares e sociais seja evitada.

Leme e Silva (1999) oferecem como alternativa para a institucionalização os centros-dia ou centros-noite, lugares onde o paciente é mantido durante turnos específicos em um local especializado, retornando para casa no final desse período, o que impede uma ruptura dos laços familiares. Sugerem que nesses locais fossem desenvolvidas atividades culturais e recreativas, incluindo intervenções intergeracionais, que mantivessem os idosos ativos e saudáveis. Brito e Ramos (1999) propõem que se deve estruturar uma rede de atenção médica específica a idosos e familiares, com programas de informações em que sejam oferecidas opções de cuidados e serviços disponíveis, assim como a maneira de utilizá-los. Isso possibilitaria que 
os idosos pudessem viver em suas casas, dentro de suas comunidades e com boa qualidade de vida. Para esses autores, a institucionalização deveria ser a última alternativa a ser cogitada.

Em sua pesquisa, Pessôa (2007) mostrou algumas possibilidades a serem consideradas antes da institucionalização. Para ela, seria necessário um maior preparo e capacitação de recursos humanos para oferecer um atendimento especializado aos idosos. Também incentiva a realização de campanhas de conscientização das famílias e da comunidade frente à responsabilidade e comprometimento com os mesmos. Junto a isso, seriam necessários maiores recursos por parte do Estado, disponibilização de diferentes políticas sociais e também a oferta de serviços que possibilitem uma alternativa à institucionalização.

A partir das representações trazidas na categoria, é possivel concluir que a família é a principal responsável pela institucionalização dos idosos. Porém, a institucionalização deveria ser considerada como uma última opção de cuidado, já que é tão importante que os idosos mantenham seus laços com seus familiares e sua comunidade. Existem alternativas anteriores à institucionalização, mas para que fossem possiveis, seria necessário um maior comprometimento das famílias, da comunidade e do Estado para com os idosos.

\section{Adaptação e mudanças na vida após a chegada à instituição}

A segunda categoria trata dos processos de mudança na vida dos idosos após sua institucionalização e a maneira como essas mudanças foram encaradas pelos mesmos. De acordo com Dias (2007), o idoso chega a uma instituição com sua história de vida e bagagem cultural e é tensionado a se desapegar disso, para se adequar às regras 
do local onde agora está inserido. Ressalta-se que cada sujeito percebe as modificações em sua vida de maneira diferente, tornando possivel o surgimento de dificuldades de adaptação. O modo como o idoso construiu sua trajetória de vida é um fator que determina a facilidade, ou não, de adaptação na instituição (CARLI et al., 2011; CARVALHO, DIAS, 2011). Entre os motivos para a existência de dificuldades nesse sentido, verificamos, conforme as falas a seguir, o sentimento de abandono de sua casa e a diminuição de contato com a família:

- [...] Foi um pouco dificil. Deixar a casa, as pessoas, as coisas tudo lá sabe. Até agora tem coisas lá ainda. Mas agora tá tudo bem (E2)

- Ah sim, lá em casa é melhor que aqui. Não tem comparação (...). Aqui foi brabo os primeiros tempos eu não gostava daqui, eu não conseguia me acostumar nesse sistema deles aqui, mas depois fui acostumando (E3).

- Pois é, acostumar a gente sabe, quando chega uma certa idade, eu tô com 78 anos, então não tem mais muita escolha, eu tava sem dinheiro e ir pra onde? Se eu quisesse ir embora, ir pra onde né, não tinha escolha mais né [...] (E1).

Como é possivel observar nas representações acima, o fato de o idoso estar implicado no processo de decisão de sua mudança para uma instituição é um dos fatores que influenciam em sua adaptação. De acordo com Carvalho e Dias (2011), idosos que são institucionalizados por não conseguirem mais cuidar de si mesmos, são os que se adaptam com mais facilidade, diferentemente dos que estão em uma instituição por problemas econômicos ou falta de outro lugar para morar.

Zimerman (2000) descreve alguns problemas que podem aparecer após a institucionalização. O primeiro corresponde às mudanças do cotidiano do sujeito, devido aos hábitos anteriores relacionados à sua casa, relações familiares 
e de amizade, rotina própria, etc. e, ao residir em uma ILPI, deve adequar-se às normas da mesma. A segunda dificuldade estaria relacionada à convivência, no que diz respeito aos demais moradores e suas diferenças como: características de personalidade, classes sociais, culturais e religiosas, que podem trazer alguns conflitos. Existem também problemas relacionados a perdas, pois as situações de morte são recorrentes nas instituições para idosos. Outro aspecto diz respeito ao abandono, pois em certos casos as famílias visitam o idoso com frequência, mas conforme o tempo vai passando elas se afastam cada vez mais. Esse fato pode desencadear doenças como a depressão ou problemas de saúde em geral. Para que isso não ocorra, torna-se imprescindivel que os familiares se organizem de modo que o idoso receba visitas periódicas e os vínculos sejam mantidos. O sentimento de abandono do idoso por seus familiares foi possivel observar, como mostra a fala:

- Tô assim com uma vontade só de chorar. Me lembro dos meus filhos lá em Venâncio Aires, dá vontade de chorar. De vez em quando um vem, mas não pode vim todos né, por causa da casa, pra cuidar. (E4).

O idoso que apresenta dificuldade na adaptação pode expressar isso por meio de seu comportamento, deixando de participar das atividades coletivas, como refeições e atividades ocupacionais que a instituição oferece (SANTOS, WACHHOLZ, 2009). Para muitos idosos, o sentimento de estar institucionalizado é semelhante ao de estar preso, pelo fato de viver em um local onde é obrigatório cumprir certas normas e rotinas, como horários para comer e até a possibilidade de sair, ou não, em alguns momentos. Esse sentimento pode se agravar nos casos de idosos que possuem alguma independência, pois a interferência da instituição em seus hábitos pode torná-los pessoas limitadas, o que gera conflitos e insatisfação (OLIVEIRA, 2006). Guedes (2008) relata que, em algumas situações, o idoso 
busca um sentimento de utilidade social, e para alcançá-lo procura na instituição atividades que lhe proporcionem a satisfação dessa sensação. Porém, a maioria deles acaba adotando uma postura de passividade e inatividade. Esse sentimento de inutilidade interfere no processo de adaptação e aceitação de sua nova realidade. $\mathrm{Na}$ entrevista com os idosos participantes, foi possivel identificar essas representações em suas falas:

- Mudou bastante (vida). É que eu estou muito preso né. Eu me sinto muito mal aqui, não consigo trabalhar, aqui eu não tô trabalhando. Me sinto muito mal, não me sinto bem aqui não. (E5).

- Os primeiros dias foram bem, quando eu era acostumado a trabalhar na CEE eu levava até um ano sem vim em casa, parava em uns barraco e andava pelo mundo velho a fora, só telefonava pra eles (E3).

Quando o idoso ingressa na instituição e é apresentado à sua estrutura e funcionamento, o passo seguinte é que ele se adapte por sua conta. Guedes (2008) aponta uma modificação nesse processo, mostrando que o ideal seria que as instituições promovessem um acompanhamento do idoso recém-chegado durante os primeiros dias, o que facilitaria sua adaptação. Além dos funcionários, poderiam ser incluídos nesse processo os antigos residentes, estimulando a formação de uma espécie de plano de integração que mobilizasse todos os moradores no planejamento de atividades. Concordando com essa ideia, Oliveira (2006) acredita que a socialização é a forma mais eficaz para uma melhor integração, pois ajuda o idoso a manifestar seus possiveis sentimentos de abandono e isolamento social, auxiliando na motivação para participação em atividades produtivas. Essas atividades proporcionam ao idoso a elevação de sua autoestima e provocam a troca permanente de ideias, sentimentos, conhecimentos e afetos com outros idosos, fazendo 
com que se sinta útil e integrado na instituição. Além disso, os responsáveis pela instituição deveriam buscar um nivel de qualidade nos serviços prestados aos residentes conforme a necessidade individual de cada idoso.

\section{Desvalorização/despersonalização do idoso}

A terceira categoria discute a desvalorização e despersonalização que os idosos sofrem ao entrarem em uma instituição de longa permanência. No momento em que o sujeito ingressa em uma instituição, inicia-se a constituição de uma nova vida, pois o mesmo precisa se desfazer de comportamentos habituais e, de certo modo, romper com sua cultura. Essa situação provoca uma transformação na percepção de si mesmo, que pode levar à baixa autoestima, frustração, decepção, impotência e autopunição (FAGUNDES et al., 2016). Para Ximenes e Côrte (2010), o fato de os idosos não se identificarem com o local onde residem, em se tratando de instituições, evidencia o surgimento, nesses sujeitos, de sentimentos de isolamento e perda da individualidade que conduzem a um processo de segregação, que torna o local onde vivem um espaço sem qualquer significado pessoal.

De acordo com Fagundes et al. (2016), durante a institucionalização vai se consolidando um movimento de despersonalização no idoso. Isso ocorre na instituição pesquisada, porque quando o idoso entra na nova residência com seus pertences, roupas, cosméticos ou outros itens de uso pessoal, esses objetos lhe são retirados e são oferecidos em troca materiais de inferior qualidade que, em sua maioria, já foram utilizados por outros idosos. Esse fato interfere diretamente na individualidade do sujeito que é tratado de forma impessoal e assim é desprezado em suas particularidades. O sentimento de despersonalização frente à retirada dos próprios pertences foi expresso na seguinte fala: 
- A gente não precisa de muita coisa. (...) Eu só queria poder ficar com as minhas coisas, que eu trouxe de casa quando a gente veio. Eu tinha trazido umas roupas novas que eu tinha comprado e também um álbum de fotos, com as fotos deles quando eram nenê. Mas eles pegaram e eu não sei aonde tá. Eu já perguntei pra eles bastante vez, mas eles sempre dizem pra falar com não sei quem, que nunca tá ou que nunca sabe. Só isso eu queria, ter as minhas coisas sabe né (E2).

- [...] eu gostava que pudesse assim ó, podia ter uma coisinha pequena com gaveta, podia ter uma chavezinha, podia chavear, eu podia botar um chocolate meu, que chocolate meu não faz mal também né, podia botar umas bolacha (...). Isso que é o que mais me invoca, o que eu mais nojo tenho daqui, que eu não posso ter nada (E1).

Na tentativa de conservar um mínimo de singularidade, os residentes buscam personalizar seus quartos com o que resta de seus objetos próprios: toalhas de mesa, flores artificiais, etc. (FAGUNDES et al., 2016). Porém, nem sempre isso é permitido nas instituições; na ILPI em estudo apenas residentes independentes podem ter objetos e roupas pessoais, sendo o cuidado destes de sua responsabilidade. Segundo Daniel (2006), as instituições que abrigam idosos deveriam favorecer que os residentes possuíssem um espaço individualizado, visto que a instituição será sua residência até o final da vida e a última chance de preservar sua identidade. Porém, por mais individualizado que esteja seu ambiente, o sujeito terá uma sensação de não pertencimento àquele local, pois sempre existirá um desejo de voltar para sua antiga casa, seja pelas recordações ou pelo sentimento de posse e referência que aquele lugar transmite (OLIVEIRA, 2006).

Para Guedes (2008), a despersonalização se intensifica após o período inicial de integração na instituição, pois ocorre uma adequação à vida cotidiana e, com isso, o sujeito é cada vez mais retirado de sua individualidade. Colabora para essa situação o fato de que as relações com a família, amigos e vizinhos vão se tornando limitadas. 
Além disso, o fato de o idoso residir em um local fechado onde desempenha sempre as mesmas tarefas com as mesmas pessoas, nas horas preestabelecidas e correspondendo a condições da instituição e não a desejos pessoais, faz com que o mesmo delimite suas vivências e tenha muito sofrimento (HERÉDIA, CORTELLETTI, CASARA, 2004). Observamos a impossibilidade de concretizar a própria vontade na seguinte fala:

- Então agora, quanto tempo que eu tô sofrendo aqui com o meu pé, eu queria que eles me levassem pro médico, nem que pagasse a consulta particular né, não mas tem que ser vigorosamente como é aqui né (E9).

Sobre o cotidiano dos idosos, Guedes (2008) refere que durante a semana, normalmente são realizadas atividades com os residentes que, relativamente, preenchem e trazem modificações na rotina. Porém, os finais de semana acabam sendo mais solitários, principalmente pela falta de ocupações. Para Correia (2007), os idosos institucionalizados possuem muito tempo livre e quando esses períodos não são preenchidos, provocam sentimentos de inutilidade e stress, levando a estados depressivos, desânimo, insatisfação e sentimento de espera da morte. Na fala a seguir fica evidente a mudança sentida pelo idoso em relação à vida levada anteriormente, na qual era possivel sair e realizar diferentes tarefas. Também está presente o fato de que a instituição não estimula a realização de atividades diversificadas:

- A minha vida mudou muita coisa né, eu saia pra lá e pra cá, ia pra cidade, pro centro, fazer compras e ia fazer uma coisa, vender, agora não vou, não saio mais, agora eu tô aqui. (...) eles não deixam fazer nada. Assim como eu tava sentada, eles não deixam fazer nada (E4).

Para Guedes (2008), as atividades a serem desenvolvidas nas instituições devem estar focadas nas necessidades 
dos idosos com diferentes potencialidades. Uma possibilidade a ser adotada é a participação em atividades voluntárias, como artesanato e jardinagem, que ajudam o idoso a diferenciar-se, através do trabalho realizado na instituição (FAGUNDES et al., 2016). Inclusive deve-se estimular que os próprios residentes auxiliem no planejamento e gerenciamento dessas atividades e também do dia a dia da instituição, pois dessa forma é possivel desenvolver maiores sentimentos de pertença ao local.

À guisa de conclusão, para impedir a continuidade do processo de despersonalização, é de fundamental importância que as instituições de longa permanência levem em consideração os seguintes aspectos: respeito à individualidade dos idosos, a autonomia, favorecimento da realização de tarefas que potencializem suas capacidades e habilidades, manutenção dos vínculos familiares e afetivos, favorecimento na criação de novos vínculos de amizade dentro da ILPI. Também é importante que a instituição tenha como seu objetivo prioritário o bom acolhimento dos idosos e um interesse genuíno em oferecer as melhores condições de vida possiveis aos que permanecerão até os últimos dias de sua vida residindo nesses locais.

\section{Considerações finais}

O estudo teve como objetivo identificar as representações sociais de idosos residentes em uma instituição de longa permanência, sobre o seu processo de inserção e adaptação ao local. Com base nas representações sociais evidenciadas na pesquisa, percebeu-se a grande influência que a institucionalização tem sobre a identidade dos idosos. Inicialmente, os entrevistados foram questionados a respeito dos motivos relacionados à sua institucionalização e, com maior ênfase, os filhos são responsabilizados, nem sempre partilhando essa decisão com o familiar idoso. 
Quanto ao processo de adaptação, é relatado em sua maioria como apresentando dificuldades, principalmente pelo fato de que os idosos precisam se desapegar de seus pertences e de sua rotina de casa, que os remetiam a seu antigo lar, e pela limitação de sua autonomia de maneira geral. Nesse sentido, a instituição acaba por contribuir com a despersonalização do idoso quando retira seus objetos pessoais e coloca como regra que ele utilize pertences de forma coletiva (roupas indiscriminadas), impedindo que seja expressa nesses objetos sua individualidade.

Concluimos parcialmente essa pesquisa, estimulando que outros estudos possam ser realizados com o intuito de desvelar a realidade por trás das instituições de longa permanência para idosos, através da perspectiva dos próprios residentes, como buscamos mostrar na presente investigação. A elucidação das representações sociais dos idosos sobre a sua própria institucionalização pode auxiliar na construção de alternativas positivas de adaptação e auxílio na transição casa-instituição, a ser realizada em um processo conjunto, que busque amenizar o possivel sofrimento advindo dessa situação, sem interferir na singularidade do idoso e respeitando a história de sua existência. 


\section{Referências}

AMARO, M. M. G. A Transformação da Identidade em Idosos Institucionalizados - Um Estudo de Casos Múltiplos. 2013. Dissertação (Mestrado em Educação). Brangaça: Escola Superior de Educação, 2013.

BARDIN, L. Análise de Conteúdo. Edições 70. Lisboa, Portugal, 1977.

BASSIT, A. Z; WITTER, C. Envelhecimento: Objeto de estudo e campo de intervenção. In: WITTER, G. P. (Org.). Envelhecimento: Referenciais teóricos e pesquisas. Campinas, SP: Editora Alínea, 2006.

BESSA, M. E. P; SILVA, M. J. Motivações para o ingresso dos idosos em instituições de longa permanência e processos adaptativos: um estudo de caso. Texto Contexto - Enferm. Florianópolis, v. 17, n. 2, p. 258-265, 2008.

BORN, T. Cuidado ao Idoso em Instituição. In: NETTO, Matheus Papaléo. Gerontologia: A velhice e o envelhecimento em visão globalizada. São Paulo: Editora Atheneu, 1999.

BRASIL. Lei 13.146, de 6 de julho de 2015. Institui a Lei Brasileira de Inclusão da Pessoa com Deficiência (Estatuto da Pessoa com Deficiência). Diário Oficial da União, 2015.

BRITO, F. C; RAMOS, L. R. Serviços de Atenção à Saúde do Idoso. In: Gerontologia: A velhice e o envelhecimento em visão globalizada. São Paulo: Editora Atheneu, 1999.

CAMARANO, A. A; KANSO, S. As instituições de longa permanência para idosos no Brasil. Rev. bras. estud. popul., São Paulo, v. 27, n. 1, p. 232-235, 2010.

CARLETTI, S. M. M; REJANI, M. I. Atenção Domiciliária ao Paciente Idoso. In: NETTO, Matheus Papaléo. Gerontologia: A velhice e o envelhecimento em visão globalizada. São Paulo: Editora Atheneu, 1999. 
CARLI L. et al. Sentimentos e percepções de idosos residentes em uma instituição asilar. Rev. Contexto \& Saúde, Ijuí, v. 10, n. 20, p. 499-506, 2011.

CARVALHO, M. P. R. S; DIAS, M. O. Adaptação de idosos institucionalizados. Milenium, 40, 161-184, 2011.

CORREIA, P. S. S. Velhos são os trapos: Mito ou realidade? Psicologia.pt - O Portal dos Psicólogo, 2007. Disponível em: <http:/ /www.psicologia.pt/artigos/textos/A0340.pdf>. Acesso em: 27 maio. 2016.

DANIEL, F. O Último Lugar no Mundo: Considerações e Reconsiderações sobre Espaço e Velhice. Interações, [S.1.], n. 11, out. 2006.

DIAS, I. G. A institucionalização asilar na percepção do idoso e de sua família: o estudo do "Lar dos Velhinhos" - Viçosa/ MG. 2007. Dissertação (Mestrado em Economia Doméstica). Minas Gerais: Viçosa, Universidade Federal de Viçosa, 2007.

FAGUNDES K. V. D. L. et al. A perspectiva etnográfica no mundo-vida de pessoas idosas em Instituição de Longa Permanência. CIAIQ16, v. 2, 2016.

FILHO, P. C. T; FILHO, J. F. P. Causas da inserção de idosos em uma instituição asilar. Escola Anna Nery Revista Enfermagem, v. 6, n. 1, p. 135-143, 2002.

GODOY, A. S. Introdução à pesquisa qualitativa e suas possibilidades. Revista de Administração de Empresas. São Paulo: Abril, v. 35, n. 2, 1995.

GOFFMAN, E. Manicômios, prisões e conventos. São Paulo: Editora Perspectiva S.A, 1996.

GUARESCHI, P. Psicologia Social Crítica: como prática de libertação. Porto Alegre: Edipucrs, 2004. 
GUEDES, J. Desafios identitários associados ao internamente em lar. VI Congresso Português de Sociologia, 2008. Disponivel em: <http://www.aps.pt/vicongresso/pdfs/339. pdf.> Acesso em: 14 abr. 2016.

HERÉDIA, V. B. M; CORTELLETTI, I. A; CASARA, M. B. Institucionalização do idoso: identidade e realidade. In: CORTELLETTI, I. A; CASARA, M B; HERÉDIA, V. B. M. (Org.). Idoso Asilado: um estudo gerontológico. Caxias do Sul: Educs, 2004, p. 13-60.

JODELET, D. Représentations Sociales: un domaine em expansion. In: JODELET, D. Les représentations sociales (dir.). Paris: PUF, 2007.

JOVCHELOVITCH, S. Os contextos do saber: representações, comunidade e cultura. Trad. Pedrinho Guareschi. Petrópolis: Vozes, 2008. (Coleção Psicologia Social)

LEME, L. E. G; SILVA, P. S. C. P. O Idoso e a Família. In: NETTO, Matheus Papaléo. Gerontologia: A velhice e o envelhecimento em visão globalizada. São Paulo: Editora Atheneu, 1999.

MINAYO, M. C. S. O desafio do conhecimento: pesquisa qualitativa em saúde. 10. ed. São Paulo: Hucitec, 2007.

MOSCOVICI. A psicanálise, sua imagem e seu público. Trad. de Sonia Fuhrmann. Petrópolis: Vozes, 1961/2012. (Coleção Psicologia Social)

MOSCOVICI, S. Representações Sociais: investigação em psicologia social. Trad. de Pedrinho Guareschi. Petrópolis: Vozes, 2003. (Coleção Psicologia Social)

OLIVEIRA, C. C. de. Otimizando a qualidade de vida das pessoas idosas institucionalizadas. Revista virtual Textos \& Contextos, n. 6, 2006. 
PERLINI, N. M. O. G; LEITE, M. T.; FURINI, A. C. Em busca de uma instituição para a pessoa idosa morar: motivos apontados por familiares. Revista da Escola de Enfermagem da USP, São Paulo, v. 41, n. 2, p. 229-236, 2007.

PESSÔA, E. M. Politicas Sociais alternativas à institucionalização de idosos em municípios da região das Missões no Rio Grande do Sul. 2007. Dissertação (Mestrado em Serviço Social). Pontificia Universidade Católica do Rio Grande do Sul, 2007.

SANTOS, C. B; WACHHOLZ, P. A. Participação do idoso autônomo na decisão familiar de se institucionalizar. Rev. Envelhecimento e saúde, v. 15 n. 4, 2009.

SANTOS, S. M. A. S. Idosos, família e cultura: Um estudo sobre a construção do papel de cuidador. Campinas, São Paulo: Editora Alínea, 2003.

XIMENES, M. A; CÔRTE, B. Idosos e seus fazeres na Instituição de Longa Permanência. Kairós Gerontologia - Revista da Faculdade de Ciências Humanas e Saúde, v. 13, p. 2934, 2010.

ZIMERMAN, G. I. Velhice: aspectos psicossociais. Porto Alegre: Artmed, 2000. 